\title{
Postural Mismatch in Musculoskeletal Disorders
}

\author{
Carsten Tjell and Wenche Iglebekk \\ Department of Otology, Sorlandet Hospital, \\ Arendal Otoneurologic Centre, Vennesla, \\ Norway
}

\section{Introduction}

"It is now recognized that disorders of the auditory system often affect the function of other parts of the auditory system." Further on one reads:" While most disorders of the auditory system have detectable morphologic abnormalities, hyperactive disorders lack such detectable morphologic changes, and even other objective signs are often absent. Symptoms such as tinnitus, hyperacusis, and phonophobia even involve physiological abnormalities in other parts of the central nervous system than the classical auditory pathways". This text is found as the first sentence in the latest textbook to Aage Möller, the world's grand old man of audiology [1]. This expresses a fundamental neurophysiological principle. "Something that happens one place will have consequences another place". This text concerns audiology, but it is also true for the postural control system.

A common clinical picture of a patient with generalized musculoskeletal disorder can be: neck pain, widespread musculoskeletal pain, headache, blurred vision, fatigue, aggravation by physical activities, dizziness, nausea, sleep disturbances and cognitive difficulties. They are often capable of increased work after a period of reduced activity. However, the day after activities their symptoms are increased. A stereotypical pattern is that the symptoms fluctuate in relation to the level of activity including static use of the eyes in relation to work at personal computer. Many of these patients are on sick leave or disabled.

Postural control system plays an important role in patients with musculoskeletal disorders. The following text will highlight six main subjects and present some studies: 1) a synopsis of the postural control system; 2) the difference between compensation of a dynamic postural disorder in contrast to a static one; 3 ) the chronic benign paroxysmal positional vertigo (BPPV); 4) the effects of the the sensorimotor system; 5) the diagnosis; 6) the treatment.

\section{Synopsis of the postural control system}

The postural control system includes the vestibular-, the visual- and the sensorimotor systems. To control equilibrium, the brain continuously receives signals from the vestibular receptors of the inner-ear, the retina of the eye, and the "proprio-ceptors" of the neck as well as many other postural "proprio-ceptors" in the body. Afferent information from the vestibular-, visual- and sensorimotor system converges in multiple areas within the central 
nervous system and is important for general equilibrium, body orientation and oculomotor control. Abnormal afferent input from these systems can result in abnormal postural control. The resulting mismatch which may occur in the presence of conflicting afferent information is thought to underlay symptoms of dizziness and unsteadiness [2].

The vestibular organ registers change in velocity, i.e. acceleration, both as rotation and as linear horizontal and vertical movements. The vestibular nuclei (VN) complex in the brainstem receives signals from the different receptors of the labyrinth. The VN complex is the origin of the different vestibular reflexes: the vestibulo-ocular reflex, the lateral and medial vestibulo-spinal reflexes as well as the vestibulo-reticular reflex [3].

When we are moving, clear vision is secured by the vestibulo-ocular reflex which engages the extra orbital muscles [4]. When we follow a moving visual target, the trajectory involves the accessory optic tract to the floccule of cerebellum [5]. There, it is integrated with the vestibular signals and continues to $\mathrm{VN}$ complex and finally involves the extra orbital muscles. The peripheral vision involves the optokinetic system which also is integrated in the VN complex as well as the cerebellum and the median parapontine reticular formation. [6]. The saccadic eye movement system enables us to bring an interesting visual object of the periphery into the fovea. The saccade system is also responsible for correcting the vision after an exaggerated vestibular stimulation like doing a pirouette. [2].Furthermore, there are not only efferent signals from the $\mathrm{VN}$ complex to the extra orbital muscles, but also afferent back to the VN complex $[7,8,9]$.

The equilibrium is secured through vestibulo-spinal [10] and vestibulo-reticular reflexes [11]. The lateral vestibulo-spinal reflex is involved in control of torso and extremity muscle tension. The medial vestibulo-spinal reflex controls muscles tonus of the neck [12].The reticular formation fine- tunes the muscle tonus.

Figure 1 presents a very simplified survey of the postural control system.

To summarize, afferent information from the vestibular, visual and sensorimotor systems converges in multiple areas within the CNS and is important for general equilibrium, body orientation and oculomotor control. Abnormal afferent input from these systems can result in impaired postural control and is thought to underlay symptoms of dizziness or unsteadiness [2].

\section{Static and dynamic vestibular dysfunction}

In a stable condition of impaired vestibular function e.g. after a vestibular neuritis, the labyrinth on one side transmits erroneous signals, but always the same wrong signal to the same movement. The VN complex compensates this loss by adjusting facilitating and inhibitory activity of the contralateral VN complex [13]. This compensation is achieved through repetitions according to Hebb's principle about neural plasticity "fire together wire together" [14]. Under normal conditions an individual will compensate a stable vestibular hypo-function, even a total loss within three months. If the individual practice vestibular rehabilitation, the normalization will occur even faster. On the other hand, in the same way it is impossible to compensate a dysfunction caused by a benign paroxysmal positional vertigo (BPPV), since the affected side transmits various abnormal signals to the same stimuli, i.e. the movements of the head. The balance dysfunction in a BPPV is dynamic and not a static one. This is probably why their symptoms are ongoing. 


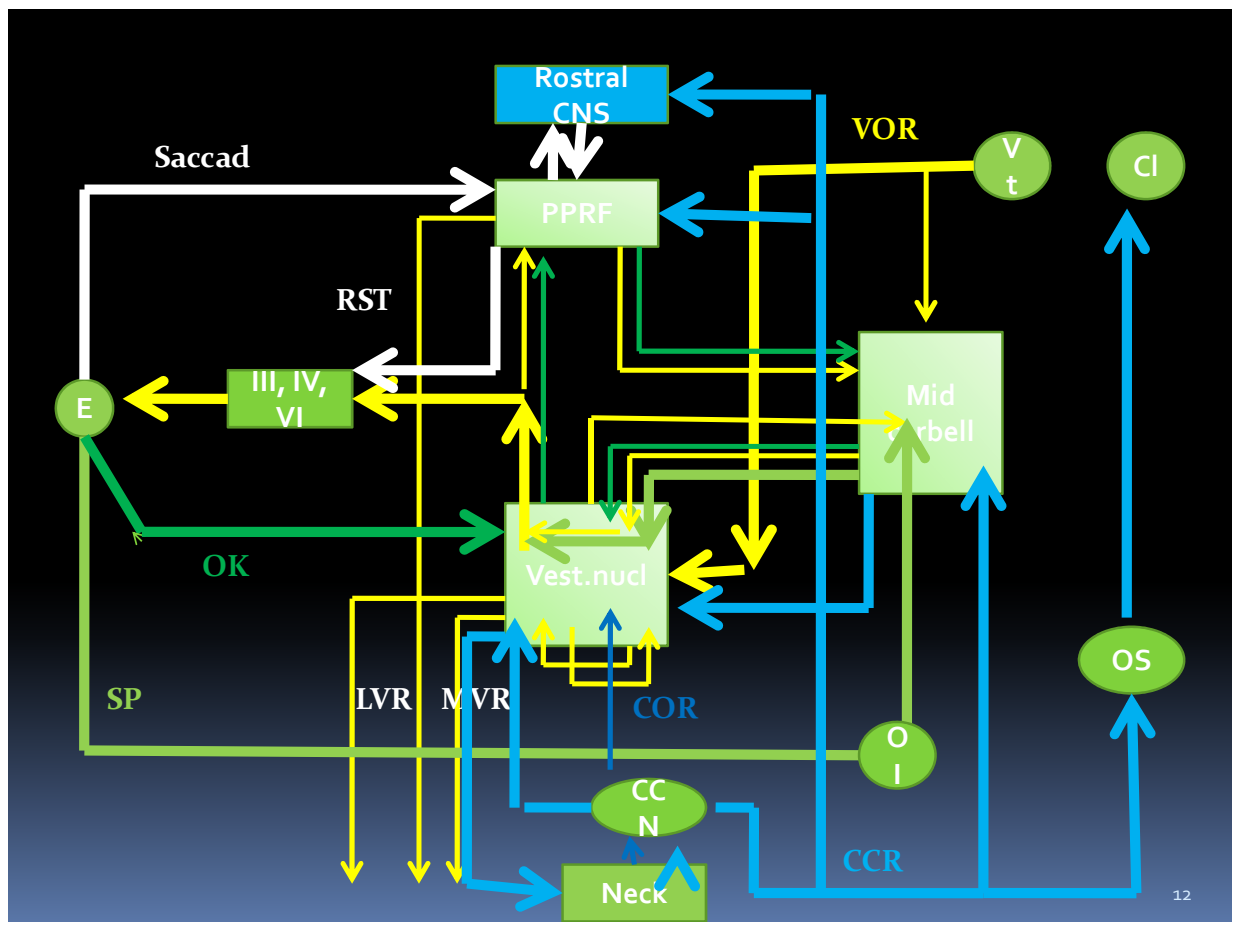

Fig. 1. Simplified survey of the postural control system. Each arrow represents four tracts: excitatory- and inhibitory- on right and left side. $\mathrm{CCN}$ : central cervical nucleus; CCR: cervico-collic relex Cl: Cochlea; CNS: central nervous system; COR: cervico-ocular reflex; E: the eye including the retina and the orbital muscles; LVR: lateral vestibulo-spinal reflex; Midcerebellum: the floccules of midcerebellum; MVR: medial vestibulo-spinal reflex; Neck: upper cervical spine with profound muscles; OK: optokinetic tract; OI: inferior olive; OS: superior olive; PPRF: median parapontine reticular formation; RST: reticular saccadic tract; Saccad: afferent saccadic tract; SP: smooth pursuit eye movement tract; Vest.nucl: vestibular nuclei complex; VOR: vestibulo-ocular reflex; VT: the vestibulum; III, IV, VI: occulomotor-, trochlear- and abduscens nerves;

\section{Benign paroxysmal positional vertigo (BPPV)}

BPPV is the most frequent cause of vertigo and dizziness. The utriculus and sacculus of the labyrinth contain small calcium carbonate particles, i.e. otoliths. The cilia of the macular hair cells are embedded in this membrane and are displaced by sharing forces applied to the membrane. The shearing forces are produced by linear acceleration, in particular by gravity. If some of these otoliths find their way into a semicircular canal, changes in head position will shift the otoliths and displace the cupula, mostly indirectly by fluid movement. This is different from time to time since the debris moves freely in the semicircular canal. The cupular displacement results in an exaggerated response from the actual labyrinth and a normal one from the contra lateral. BPPV was first described 1921 by Barány [15] and coined 1952 by Dix and Hallpike [16]. The condition is characterized by “...brief attacks of rotatory 
vertigo and concomitant positioning rotatory-linear nystagmus elicit by rapid changes in head position relative to gravity" [3]. According to this statement an individual without rotatory vertigo is considered not to suffer from BPPV. However, as Norré described [17], and confirmed by the authors that patients with chronic BPPV, i.e. more than 6 months duration, is not always characterized by rotatory vertigo [18]. Diffuse dizziness, vertigo, blurred vision, headache, neck- and widespread musculoskeletal pain, nausea, sleep disturbances, fatigue, cognitive difficulties are symptoms found in patients with chronic BPPV. Many also suffer from tinnitus. They dislike being in certain environments causing peripheral visual disturbances. An example includes busy shopping centers. This clinical picture is also observed in patients who fulfill the criteria of whiplash associated disorders (WAD) [19] and in patients with idiopathic neck disorders [20].

Thus in the chronic BPPV patient, the VN complex receives perpetual contradictive signals from the different receptors of the labyrinth. As described earlier the VN complex is the origin of the different vestibular reflexes: the vestibulo-ocular reflex, the lateral and medial vestibulo-spinal reflexes as well as the vestibulo-reticular reflex. Further on the VN complex is important in the sensorimotor control system.

The varying contradictive signals through the vestibulo-ocular reflex are the cause of visual disturbances. In addition vision is affected by various systems which all involve the VN complex. This leads to a static orbital muscular contraction in an attempt to secure clear vision which could be the cause of the retro- and periorbital headache.

Due to this mismatch in the signals from the VN complex the extremities-, torso- and neck muscles also go into a static contraction. This is to secure the equilibrium.

\section{Effects of the the sensorimotor system}

The human body, with a highly placed centre of gravity, with many adjustable segments on top of each other and a very small support of base, is maladjusted for vertical balance. The advantage with this multisegmental construction allows the equilibrium to maintain in many different positions, also when moving [21].This amount of information processing is a challenge for the brain. It is therefore easy to comprehend the fact that some people suffer from balance disorders. It is, on the other hand, remarkable that the majority of people do not.

Proprioception can be defined as the sensation of position and movements at joints; the sense of force and effort associated with muscular contraction; or the sensation of perceived timing of muscular contraction [22]. Sensory input from mechanoreceptors in muscles (e.g. muscle spindles) joints and skin is processed by the central nervous system (CNS) to form internal models of body configuration [23]. The CNS uses these models for motor coordination [24]. The cervico-collic reflex (CCR) has inter alia the origin in the gamma muscle spindles in the profound cranio-cervical muscles. Afferent signals of the CCR are transmitted to the important postural control centres, i.e. the mid-cerebellum, the VN complex and the reticular formation. The CCR has a high sensitivity to small stimuli and a lower sensitivity for larger neck rotations, which suggests that muscle spindles rather than joint receptors provide the major input to the CCR [25-27]. Thus proprioceptive information from the muscle spindles is crucial for optimal motor control. Therefore, it seems reasonable to presume that improper proprioceptive activity would lead to reduced postural control. 
To highlight this: due to the very high density of gamma muscle-spindles in the craniocervical joint related deep muscles [28-30] they are considered to be the most important proprioceptive postural functional units. A reduced postural control generates erroneous head and neck position as well as a disturbed movement pattern. Studies have shown that chronic neck pain patients have a disturbed neuromuscular control [20,31,32,33]. As the discs are the load bearing structure in the lumbar spine, the facet joints takes most of the loads in the cervical spine. Decreased neuromuscular control results in functional joint instability which leads to an insidious pattern of repetitive abnormal loading [34], which results in pain and articular damage. The BPPV from one labyrinth leads to increased afferent activity and a relative hypo-activity of the opposite labyrinth. This in turn leads to a compensating medial- and lateral vestibulo-spinal activity. It is quite common that a neck disorder caused by a postural mismatch leads to widespread musculoskeletal pain. Chronic BPPV has been observed in patients with frozen shoulder.

Individuals with work-related chronic muscle dysfunction suffer from a mismatch in the gamma-muscle spindle activity. Muscle spindles are considered to be the most important muscle mechanoreceptors for proprioception [35]. Their main functions are to record movements and positions, to be involved in muscle co-ordination and to regulate the nerve mediated muscle stiffness. Studies have shown a close relationship between gamma muscle spindles and chronic inflammation in painful muscle disorders [36,37]. During muscle contraction different substances are produced in the muscle (e.g. lactic acid, arachidonic acid, bradykinin and serotonin) [36,37]. Moreover, bradykinin injection into cervical facet joints [38] as well as the temporomandibular joint [39] was shown to affect the stretch sensitivity of the neck muscle spindles. Evidence suggests that the acuity of proprioceptive information from muscle spindle afferents can be impaired by fatigue, inflammation as well as trauma [35]. These items stimulate the chemoreceptors of the muscles [40], which via the gamma cells in the spinal medulla activate the gamma muscle spindle system. Studies have documented impaired postural control through abnormal head repositioning in patients suffering from chronic neck pain of both traumatic and non-traumatic aetiology $[32,33,41-$ 43].

The gamma cells in the spinal medulla not only activate the gamma muscle spindle system, but they also mediate important postural information to the brain via the central cervical nucleus $(\mathrm{CCN})$ in the middle of the cervical spine [44-46]. The signals are transmitted to the most important locations for the postural integration and balance, i.e. midcerebellum, the $\mathrm{VN}$ complex and the paramedian pontine reticular formation of the brainstem. In individuals with idiopathic neck disorder the proprioceptive input alone is probably not capable of creating a postural mismatch. However, in the presence of a BPPV, a postural mismatch occurs. The integration of various visual and vestibular signals normally occurs in the midcerebellum without any problem. However, in an individual with chronic BPPV and secondarily a dysfunction in the cervical proprioceptive activity, the integration will be disturbed and will provoke dizziness [47]. These patients are under a steady barrage of misleading vestibular and proprioceptive signals from the neck which create continuous compensatory neck muscle tension of varying intensity (via the vestibulo-spinal reflexes, $[10,11])$. This increased muscle tension causes the release of substances such as arachidonic acids and the process is ongoing. Thus, the vicious circle of the equilibrium control system is also responsible for the vicious circle of pain [48]. 


\section{Diagnosis}

The Dizziness Handicap Inventory (DHI) [49] is validated for individuals with vestibular dysfunction. This tool consists of 25 items that are scored as always (4 points), sometimes (2 points), and never ( 0 point) for a total score of 100 . A score $>60$ is related to an increased likelihood of having a fall (Figure 2). Most patients with chronic BPPV have a score beyond 30 [18].

\section{Dizziness Handicap Inventory}

\section{Always /Sometimes /Never}

P 1. Does looking up increase your problem?

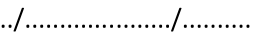

E 2. Because of your problem, do you feel frustrated? /

F 3. Because of your problem, do you restrict your travel

for business or recreation? . .1 /

P 4. Does walking down the aisle of a supermarket increase your problem? .............. $. / \ldots \ldots . . .$.

F 5. Because of your problem, do you have difficulty getting into or out of bed? /. .../

F 6. Does your problem significantly restrict your participation in social activities such as going to the movies, dinner, dancing, parties? $/ \ldots$ $. / \ldots \ldots . . . .$.

F 7. Because of your problem, do you have difficulty reading? .../......... ....

P 8. Does performing more ambitious activities like sports, dancing, household chores such as sweeping, putting dishes away increase your problem?

E 9. Because of your problem, are you afraid to leave your home without having someone accompany you? ................../

E 10. Because of your problem, have you been embarrassed in front of others?

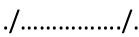

P 11. Do quick movements of your head increase your problem?

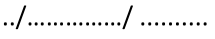

F 12. Because of your problem, do you avoid heights?

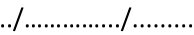

P 13. Does turning over in bed increase your problem?

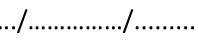

F 14. Because of your problem, is it difficult for you to do strenuous housework or yard work?

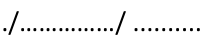


E 15. Because of your problem, are you afraid people may think

you are intoxicated?

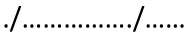

F 16. Because of your problem, is it difficult for you to go for a

walk by yourself?

P 17. Does walking down a sidewalk increase your problem? $\quad$.......................................

E 18. Because of your problem, is it difficult for you to concentrate?............................

F 19. Because of your problem, is it difficult for you to walk around

your house in the dark? ......................................................................................

E 20. Because of your problem, are you afraid to stay home alone? ................................

E 21. Because of your problem, do you feel handicapped?

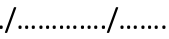

E 22. Has your problem placed stress on your relationships with

members of your family and friends? ...............................................................

E 23. Because of your problem, are you depressed? $\quad$..................................

F 24. Does your problem interfere with your job or household

responsibilities? .........................................................................................

P 25. Does bending over increase your problem? ....................................................

Total score $=$

(P,physical; E, emotional; $F$, functional.)

\section{Fig. 2. Dizziness Handicap Inventory}

The Clinical Test of Sensory Interaction and Balance (CTSIB) [50] is a useful instrument. Standing with eyes closed on an unstable surface is the most challenging part of the test. Dix-Hallpike test [16] is the ordinary clinical test for demonstrating BPPV; however it is not sufficiently sensitive. Even with video-oculoscopy it is difficult to observe delicate discrete nystagmus in patients with chronic BPPV. Moreover, in the chronic conditions dizziness is the dominant symptom, sudden vertigo occurs in only $20 \%$ [18]. In the standard test procedure the patient is positioned and observed during 30 seconds. About $15 \%$ of the subjects have a latency of more than one minute before nystagmus occurs. 
The diagnosis BPPV is objectified by demonstrating nystagmus when the patient is positioned in a Dix-Hallpike position or in the first position of a Brandt-Daroff maneuver, i.e., lying down on one side [51]. The nystagmus is registered by video-oculography (Interacoustics A/S, Assens, Denmark) (Figure 3). This technique allows identification of nystagmus occurring intermittently, as well as after a long latency. Each positioning is done in slow motion, and the subject is kept for three minutes in each position. The gravity constituted the acceleration. Otoliths in one SSC give a specific nystagmus pattern. Otoliths in more than one SSC give various nystagmus patterns depending on which SSC is activated and the amount of debris present. The resulting nystagmus is expressed as a vector. Divergence from one-SSC pattern is interpreted as a BPP with otoliths in more than one SSC.

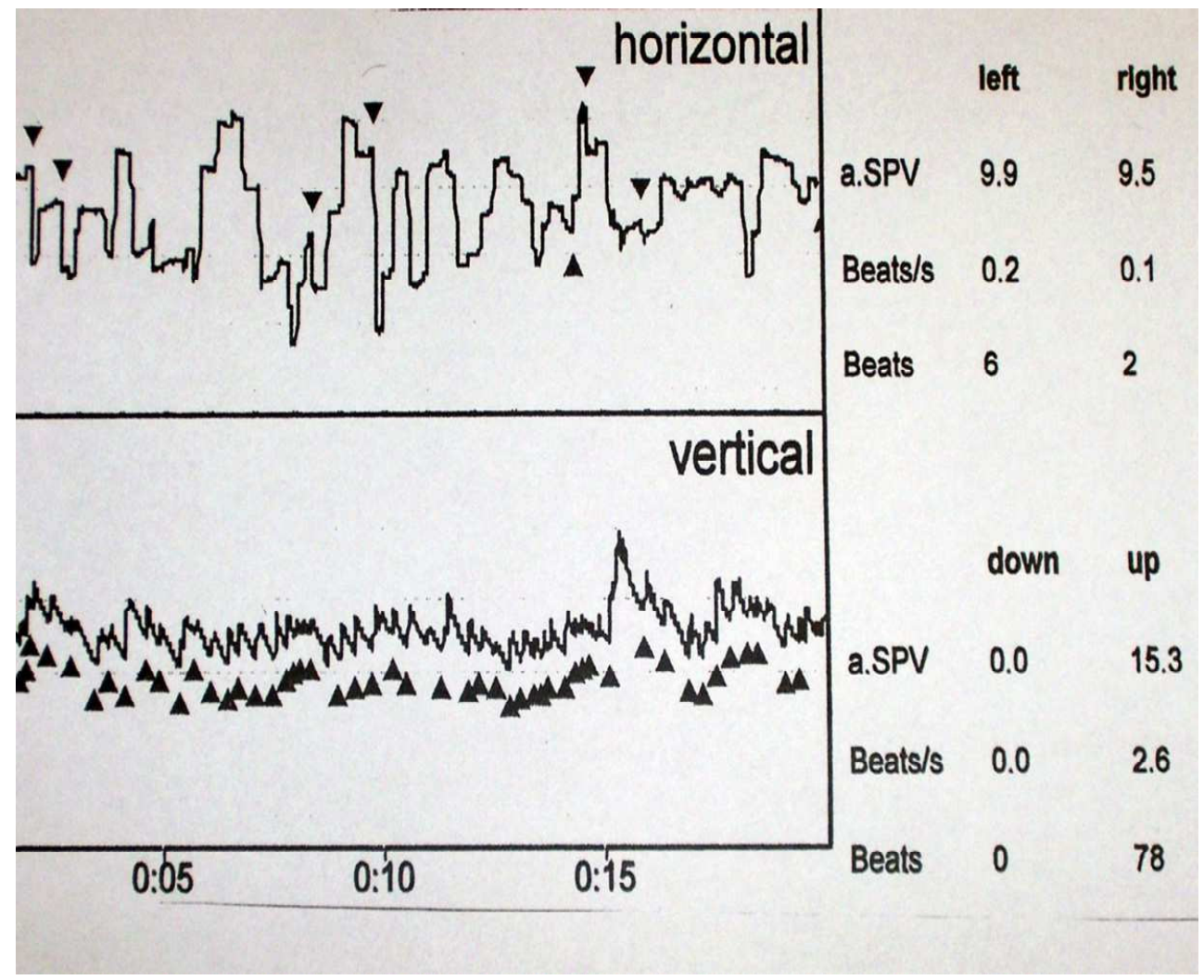

Fig. 3. The video-oculography documents a BPPV (Interacoustics A/S, Assens, Denmark). The patient was tested in the Brandt Daroff position for three minutes; no nystagmus was registered when she was lying down, neither in the Dix-Hallpike position. First in the sitting position nystagmus occurred. The illustration demonstrates a sequence after one minute in the sitting position. The intensive nystagmus was ongoing and after three minutes the patient was allowed to gaze to control the dizziness and nausea.

The patient is a 35 year old woman with a head and neck trauma ten years back and she has had intermittent symptoms. She has the clinical picture of a long lasting BPPV. Her earlier given diagnosis was phobic postural vertigo. 
Video-oculography for Smooth Pursuit Neck Torsion (SPNT) test [52,53]. This test is relevant to perform, if there is a history of neck trauma. The registration is done by binocular videooculography (Interacoustics A/S, Assens, Denmark). This equipment is full digital without any analogue parts. The SPNT test is partly a conventional test of the smooth pursuit eye movement test and partly a test of the proprioceptives of the neck. We used a moving sinusoid stimulus with a maximum velocity of 20 degrees per second. This test has to be performed after at least five minutes of rest without any movement of the head. The test starts with the subject facing the target (a yellow dot on a screen) without turning the head in relation to the torso (neutral position). Six cycles were performed. The torso of the subject was then actively turned away from the screen and kept in a static position at a maximum angle of 45 degrees - or at some angle which did not increase pain, stress and / or discomfort in this position - with the head held in a horizontal position facing the screen. After a short pause, the visual stimulus was again presented. The test was then repeated in the opposite direction. The ability to follow the target is expressed as a gain, i.e. the proportion between the movement of the eyes and the movement of the target. The average gain of each head position in relation to torso and direction of the eye movements were recorded. The test parameter chosen to represent the SPNT test was called the SPNT (diff) is defined by the algorithm:

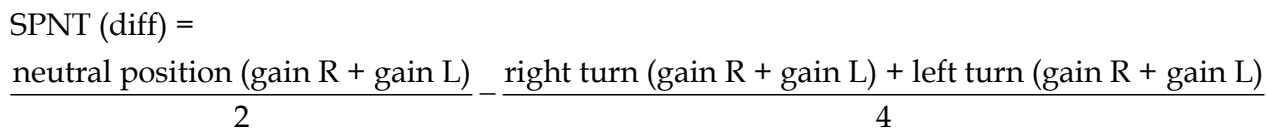

Gain $\mathrm{R}$ represents the gain of smooth pursuits, tracking a target which moves to the right; gain $\mathrm{L}$ represents the corresponding gain to the left.

A positive SPNT test seems to be an expression of a serious neck dysfunction. In our study only $30 \%$ of patients who fulfill the Quebec Task Force criteria of a WAD have a positive SPNT test [54]. If the patient has not rested for five minutes before the start of the test, there is a risk of a false positive test result. This is due to the effects of BPPV.

\section{Treatment}

\subsection{General principle of treatment}

A balance disorder is either due to abnormal afferent signals from the periphery or abnormal processing in the CNS. If a balance disorder is static, the central postural control system will compensate and the condition will improve. This is the normal course after a vestibular neuritis, labyrintitis and lacunar brain stem- or cerebellar infarcts. In the opposite situation where the activity of the peripheral balance organ varies from time to time, the central postural control system has limited possibility to compensate. This is a well-known phenomenon in Ménière 's disease and in BPPV. When the otoliths are displaced from the semicircular canals in BPPV, the signals from the labyrinth will be ameliorated. The more normalized a balance unit can function; the less stabilizing vestibulo-spinal and vestibulo-ocular reflex activity is needed [3].

A neck with an abnormal movement pattern gives an inappropriate afferent signal activity from the gamma-muscle spindles to the central postural control system primarily via the cervico-collic reflex (CCR) [25-27]. Static muscle contraction leads to increased pain [35-38]. 
This can lead to a compensating movement pattern. According to Hebb's principle about neural plasticity the individual lose the correct movement pattern ("use it, or lose it") and change it to a new erroneous one [14].

\subsection{Treatment of BPPV}

Modified Epley maneuver for repositioning of otoliths in posterior SSC [55-56]. The maneuver is carried out in slow motion, opposite the common fast procedure which intends to get benefit from the centrifugal force. It is difficult in a controlled way to move solid elements in liquid. It is more easy and controlled to do it slowly: 1) Relax in long sitting position on an exam table for five minutes to allow the otoliths to settle before repositioning. For treating the posterior SSC turn the head 45 degrees towards the affected site. 2) The patient's head is maintained in 45 degrees of rotation and then slowly brought backwards to an angle of 45 degrees under the horizontal level. 3) Hold the patient's head backwards and slowly rotate 90 degrees to the opposite side. 4) The patient is then rolled into a side lying position with their head turned 45 degrees downward towards the floor. 5) Finally, the patient returns to the sitting position. Each position should be maintained for at least three minutes.

Repositioning of otoliths in anterior SSC. This maneuver is also carried out in slow motion: 1) Relax in long sitting position on a tilting table for five minutes. Turn the head 20 degrees towards the unaffected site. 2) The patient's head is maintained in 20 degrees of rotation and the table is slowly tilted backwards to an angle of 70 degrees under the horizontal level. 3) Hold the tilted position and slowly rotate the head 40 degrees to the opposite side. 4) Finally, the table is tilted back to upright position. Each position should be maintained for at least three minutes.

Modified 360 degrees repositioning maneuver for repositioning of otolith in the lateral semicircular canal: Relax in sitting position for five minutes. Slowly lie down towards the affected side. A pillow should be placed under the patient's head. Next, slowly turn into the supine position. Then turn slowly toward the unaffected side before turning into the prone position. Each position should be maintained for at least three minutes. Finish by returning to the starting (sitting) position.

The otolith repositioning maneuver is performed twice during one treatment session. Only one SSC is treated at a time. A rest in sitting position for at least fifteen minutes after the treatment is needed. Seven to fourteen days between each treatment is recommended. The first night after repositioning the patient should sleep with the head-end elevated 45 degrees. Any kind of treatment which involves fast and uncontrolled movements is dissuaded due to the risk of spreading to other SSCs.

It is of uppermost importance that the patient is informed about a substantial risk of a temporary aggravation of all symptoms. This is due to a significant change in the postural control. This is exemplified in a case where all three SSC are involved on one side and the other side is healthy. The brain is partially accustomed to this situation. After otolith repositioning of one SSC the patient has one healthy and two diseased SSCs. This is a complete new situation for the brain; it has no experience of this combination. Therefore, all the vestibular reflexes are activated with all the symptoms. This is a well known experience when debarking after a few days at sea. Normally, this aggravation fades after a week; then 
it reappears after the next repositioning but less severe. After the last repositioning the condition usually turns positive.

It is mandatory to know that the treatment of chronic BPPV is much more complicated than treatment of the acute conditions. The acute one is nearly always a question of one SSC. Many of the simple BPPV conditions heal spontaneously. Therefore, BPPV is considered as a harmless disorder. However, many do not heal, but they change their appearance, dramatic vertigo disappears, but a lot of diffuse symptoms develop [18]. These symptoms are the consequence of reflex activity emitted from the $\mathrm{VN}$ complex. The $\mathrm{VN}$ complex receives contradictive signals from the labyrinths. It is not unusual that patients need various treatment series before improvement. According to our experience, treatment of the anterior SSC is a challenge.

\subsection{Treatment of the neck}

The treatment sessions are of sixty minutes duration and given twice a week. Every session is individualized and only the basic principles will be mentioned.

The more normalized a balance unit can function; the less stabilizing vestibulo-spinal reflex activity is needed [3]. This principle is also used for the neck. A neck with an abnormal movement pattern gives an inappropriate afferent signal activity from the gamma-muscle spindles to the central postural control system primarily via the CCR [25-27]. Increased muscle tension leads to increased pain, which leads to a compensating movement pattern. Therefore, the primary focus of management is to correct postures and movement patterns that are linked to maintaining the pain disorder. This approach is based on a motor control model whereby the faulty movement pattern or patterns are identified; the components of the movement are isolated and retrained into functional tasks specific to the patients' individual needs [34]. The treatment aims to naturally incorporate a conscious improved movement pattern into the daily life routine. In addition walking exercises outside on natural uneven grounds are recommended.

The Joint position error (JPE) test equipment is used to exercise the kinaesthesia of the neck, as well as the mid-cerebellar integration of central vision and the vestibulo-ocular reflex with neck movements [47]. This exercise is done by using a head-mounted laser pointer. The target is an adjustable wall chart with a horizontal and a vertical line creating a cross in the centre. The patient sits comfortably three meters from the wall chart. Three meters is chosen, rather than $90 \mathrm{~cm}$, as this is more demanding and better exercises the coordination of movement. The laser beam starts at the centre and then followed the horizontal line to the end $(44 \mathrm{~cm})$ and back again to the centre. -

If the patient experiences an increase of pain and symptoms, either immediately after the treatment or the following day, an adjustment of the treatment program is enforced. Moreover, the patient is on sick leave from work during the period of treatment. Patients are recommended to initially start working $20 \%$ the first month and then steadily increase.

\section{Some studies}

Finally, we want to present a couple of abstracts and some results from an unpublished study. 
Symptoms and findings in a prospective cohort study of the misinterpreted patient with long lasting benign paroxysmal positional vertigo [18].

Carsten Tjell, MD, PhD, Wenche Iglebekk, P.T.

Introduction Benign paroxysmal positional vertigo (BBPV) is characterized by short attacks of position related rotatory vertigo. Individuals with long lasting dizziness and diffuse symptoms are therefore interpreted as not suffering from BPPV.

Materials and Methods A consecutive prospective register study was performed. Sixty-nine individuals (26 with whiplash associated disorders, 30 with a history of head / neck trauma, 13 with no history of trauma) fulfilled the eligibility criteria: 1) BPPV confirmed by videooculographic documentation of nystagmus in BPPV relevant positions, 2) and positive responses during otolith repositioning maneuvers, 3) symptoms persisting for a duration of at least six months, 4) normal MRI cerebrum. The subjects answered the Dizziness Handicap Inventory (DHI) and a questionnaire concerning possible symptoms of long lasting BPPV.

Results The DHI score for all patients was medium high. More than one semicircular canal was engaged in all patients. Dizziness $(81 \%)$ is far more common than rotatory vertigo (19 $\%)$. The prevalence of various symptoms as well as the symptoms announced and findings observed during the canalith repositioning maneuvers were registered. There were no significant differences between the study groups. Sixty-nine percent were on long term sick leave.

Conclusions The clinical picture of long lasting BPPV is different from the acute BPPV. Diffuse dizziness, blurred vision, frontal headache, neck pain, nausea, sleep disturbances, cognitive difficulties are symptoms found in this patient group. The findings are nystagmus, periorbital spasm and involuntary movements of neck, torso or extremities. The majority of the patients in this study have been diagnosed with phobic postural vertigo. It also includes patients diagnosed with whiplash associated disorders (WAD) and others who believe they suffer from WAD. The common denominator amongst all these patients is a long lasting BPPV.

\section{Have we been fooled by BPPV when diagnosing WAD? Only a few seem to have a real neck injury [54]. \\ Carsten Tjell, MD, PhD, Wenche Iglebekk, P.T.}

Introduction The similarities between whiplash associated disorders (WAD) and traumatic neck disorders with intermittent symptoms constitute the background for many medico legal conflicts. Many symptoms are common among patients with long lasting benign paroxysmal positional vertigo (BPPV) and patients with WAD. Smooth pursuit neck torsion (SPNT) test has earlier been presented as a diagnostic tool. The aim of this study is to 1) find the prevalence of BPPV in the study groups; 2) to validate the SPNT test as a specific test for diagnosing WAD.

Materials and Methods A consecutive prospective register study was performed. Patients with long lasting balance disorders are referred to Otoneurology Centre in Southern Norway. These are primarily patients unsuccessfully treated by the public health care. Fiftysix individuals fulfilled the eligibility criteria: 1) neck pain caused by trauma and dizziness persisting for at least six months, 2) normal MRI cerebrum, 3) no severe eye disorders. These patients were allocated in two groups. Twenty-eight patients fulfilled the criteria of WAD 
and constituted the patient group. Twenty-eight patients with a history of head / neck trauma and intermittent symptoms constituted the control group. Amongst the controls there were patients who believe they suffer from WAD. A healthy control group of twentyfive individuals defined the range of normality. All patients answered the 1) Dizziness Handicap Inventory (DHI), 2) a questionnaire concerning possible symptoms of long lasting BPPV and 3) a visual analogue scale for pain. All subjects underwent an otoneurologic intervention consisting of 1) Clinical Test of Sensory Interaction and Balance (CTSIB), 2) video-oculography for BPPV in Brandt-Daroff as well as Dix-Hallpike position and 3) videooculography for SPNT test.

Results There were no significant group differences concerning the questionnaires and the CTSIB. A BPPV was diagnosed in all patients. More than one semicircular canal was engaged in most patients. The SPNT test was found positive in seven of the patients with WAD and in one of the control group. The sensitivity is found to be $25 \%$ and the specificity is $96 \%$. The predictive value as positive test is $88 \%$ and as negative test is $56 \%$.

Conclusions The investigation shows that BPPV plays a crucial part in WAD. The SPNT test documents a very high specificity. The degree of neck injury probably determines the sensitivity and the predictive values. It is the author's opinion that the majority of patients diagnosed with WAD in fact suffer from a long lasting BPPV. A minority of these patients suffer from both a BPPV and a neck injury. The SPNT test is most likely an instrument for identifying the real neck injuries amongst the patients with WAD.

\section{A study investigating similarities between patients with idiopathic- and traumatic neck disorders with dizziness \\ Wenche Iglebekk, P.T., Carsten Tjell, MD, PhD}

\section{Abstract}

The study entails 1) to investigate if patients without trauma are able to develop a clinical condition similar to WAD; 2) to evaluate the treatment concept. The study was a prospective consecutive cohort series which included 27 patients with idiopathic neck disorder and dizziness (INDD) (all of them suffered from BPPV). A group of 19 patients with whiplash associated disorders (WAD) were chosen as controls. All of these also suffered from BPPV. Both groups showed identical base-line data. All underwent a balance treatment program focusing on ameliorating the afferent signals from the peripheral balance units, i.e., they underwent otolith repositioning maneuvers and neck treatment. Both groups improved significantly and equally. The measurements included: visual analogue scale for pain and various activities of daily living; joint position error test; cervical range of motion; work capacity. The study brings support for the hypothesis that equilibrium plays an important role in WAD and INDD. Moreover, both the INDD and WAD patient groups responded equally and significantly to a balance treatment program focusing on amelioration of malfunction peripheral units of the equilibrium system.

\section{Material and Method}

The most complicated patients with balance disorders from three counties with a population of about 400.000 inhabitants are referred to the Centre of Audiology and Neurotology in Arendal in southern Norway. The centre receives about 400 vertigo patients per year. They are all diagnosed by one neurotologist. This study was a prospective consecutive cohort 
series made up of patients with idiopathic neck disorder and dizziness (INDD). A group of patients with WAD was chosen as controls. The patient group, INDD, included 27 patients (all suffered from BPPV); the control group included 19 patients with WAD (all suffered from BPPV) Table1. 1) The baseline data of the INDD patient and WAD control groups were compared. All patients underwent a balance oriented treatment program. 2) The pre- and post-treatment test results of both groups were compared.

The inclusion criteria for patients with INDD were idiopathic neck pain together with BPPV. The duration of the BPPV was set to at least six months.

The inclusion criteria for patients with WAD were the criteria of the Quebec Task Force [19] together with BPPV. The duration of the disorder was set to at least six months.

The exclusion criteria for this study were: 1) the presence of an asymmetric caloric response; 2) any long lasting positive effect of an earlier treatment - these strict criteria were chosen to ensure that the patients were severe victims of their conditions -; 3) a history of any CNS or psychiatric disorder as well as a serious visual handicap.

Examples of earlier given treatments are stretching, acupuncture, manipulation of the neck, work-out training, exercise in water, sling-exercise therapy, balance training and cognitive therapy.

During the period between March 2007 and September 2008 fifty patients fulfilled the inclusion criteria. They were offered treatment in a private physiotherapy clinic by one physiotherapist. Informed consent was obtained from all patients. Four patients discontinued treatment due to financial reasons ( 2 subjects) and inability to understand the given instructions (2 subjects).

\section{Treatment}

All patients underwent the otolith repositioning maneuvers, followed by treatment for neck and posture control.

\subsection{Evaluations}

The patient's status was evaluated at the first and last treatment session. The patients' work ability was evaluated three months after the end of the treatment.

\subsection{Objective tests}

JPE test of the cervical spine. The outcome is a measure of the joint position sense which is the conscious experience of the joint's position given by the proprioceptive input to the CNS. The same position used for the exercise was used for the test. The laser beam started at the centre and then followed the horizontal line to the end $(44 \mathrm{~cm})$ and back again to the centre. The movement was repeated with the eyes closed; where the laser beam stopped is where the patient experienced the centre. This point was manually indicated. Each test was performed only once due to a high level of pain in some of the patients (before start of treatment). The co-ordinates were measured in centimetres on $\mathrm{x}$ - and $\mathrm{y}$-axes. The procedure was performed to the right and to the left. The limit of a normal JPE-test was defined by the 
results of healthy members of the hospital staff: (Exclusion criteria: on sick leave due to neck disability, a history of any Central Nervous System (CNS) or psychiatric disorder as well as a serious visual handicap. $(\mathrm{n}=19)$. Table 1 .

\begin{tabular}{|c|c|c|c|c|c|}
\hline & N & Female & Age in years & $\begin{array}{c}\text { Duration of } \\
\text { disease in months }\end{array}$ & $\begin{array}{c}\text { Individuals on: No sick leave } \\
\text { /Part time sick leave/ Full } \\
\text { time sick leave/Disablement } \\
\text { pension/ Senior citizen }\end{array}$ \\
\hline INDD & 27 & 19 & $\begin{array}{c}40(27-71) \\
{[37-53]}\end{array}$ & $24(6-168)[12-60]$ & $1 / 5 / 17 / 3 / 1$ \\
\hline WAD & 19 & 13 & $\begin{array}{c}51(16-66)[37- \\
53]\end{array}$ & $96(6-344)[36-216]$ & $0 / 3 / 9 / 6 / 1$ \\
\hline $\begin{array}{c}\text { Controls } \\
\text { (JPE-test) }\end{array}$ & 19 & 11 & $\begin{array}{c}50(29-66)[40- \\
54]\end{array}$ & & \\
\hline P-value & & 0.66 & 0.85 & $0.005 * *$ & \\
\hline
\end{tabular}

INDD: Idiopathic neck disorder with dizziness; WAD: Whiplash associated disorders;

JPE-test: Joint position error test; Median values are given. Range is shown in parenthesis.

The $25^{\text {th }}$ and $75^{\text {th }}$ percentiles are shown in brackets.

P-values indicate the variance analysis of the patient- and JPE-control groups for gender and age.

The duration of disease of the INDD group is significantly shorter than that of the WAD group.

Table 1. Clinical data of the patient and JPE control groups

Neck range of motion was estimated for CROM (degree of Cervical Range Of Motion) (Performance Attainment Associates, www. spineproducts.com) based on goniometry using the principle of a compass. The following were estimated: Neck resting posture in sitting position was measured as well as flexion, extension, lateral flexion and rotation. The patient was told to stop movement when pain increased. Each movement was performed once. Furthermore, it was observed whether the neck movements were ataxic or smooth.

\subsection{Subjective tests}

\subsubsection{Visual analogue scale for pain}

The subjects were asked to indicate their average and maximum levels of pain during the last two weeks on a visual analogue scale from 0 to 10 , where 0 means no pain and 10 the worst pain imaginable.

\subsubsection{Whiplash disability questionnaire [57]}

To assess the quality of daily living activities the patients were asked to complete this Australian validated questionnaire, translated into Norwegian. Questions concerning mental status were omitted, since too many of the subjects denied to participate in the study if these questions were included. The following were included: ability to concentrate; degree of fatigue; ability to participate in social living; ability to perform physical activity; quality and length of sleep; capacity of working in and away from home; car driving. The same visual analogue scale was used, where 0 means no influence at all and 10 the greatest impact imaginable. 


\subsubsection{Dizziness and tinnitus}

The experience of dizziness and tinnitus was noted before and after treatment.

\subsubsection{Working ability / disablement pension}

The subjects were asked about their sick leave status at the first treatment session. Three months after the last session the patients gave a written answer about their post-treatment state.

\subsection{Statistical analysis}

Mann- Whitney U-test and Kruskal-Wallis variance analysis were applied for intergroup comparisons with one dependent variable. The Wilcoxon matched pairs test was used for comparing pre- and post treatment results. The StatSoft-statistical program, copyright 19842002 (Tulsa, OK 74104) was used for the analyses.

\section{Baseline results}

The baseline results in both groups showed no significant differences. Tables 2A, 3A, 4 and 5A.

\begin{tabular}{|c|c|c|c|c|}
\hline Pre-treatment & X-axe Right in cm & X-axe Left in cm & Y-axe Right in cm & Y-axe Left in cm \\
\hline INDD & $10(4-11)$ & $7(5-12)$ & $5(2-8)$ & $3(2-6)$ \\
\hline WAD & $4(3-10)$ & $5(4-9)$ & $3(0-6)$ & $4(2-7)$ \\
\hline Controls & $3(1-4)$ & $2(0-4)$ & $2(1-3)$ & $1(0-3)$ \\
\hline $\mathbf{p}$ & 0.07 & 0.55 & 0.19 & 0.59 \\
\hline$P^{*}$ & $0.0013^{* *}$ & $0.0035^{* *}$ & $0.036^{*}$ & 0.057 \\
\hline
\end{tabular}

\begin{tabular}{|c|c|c|c|c|}
\hline Post-treatment & X-axe Right in cm & X-axe Left in cm & Y-axe Right in cm & Y-axe Left in cm \\
\hline INDD & $3(2-5)[0.0001]^{* * *}$ & $3(1-6)[0.0005]^{* * *}$ & $2(0-3)[0.0004]^{* * *}$ & $1(0-4)[0.004]^{* *}$ \\
\hline WAD & $\begin{array}{c}1(0-3) \\
{[0.006]^{* *}}\end{array}$ & $3(2-5)[0.04]^{*}$ & $0(0-2)[0.004]^{* *}$ & $1(0-2)[0.0009]^{* * *}$ \\
\hline Controls & $3(1-4)$ & $2(0-4)$ & $2(1-3)$ & $1(0-3)$ \\
\hline $\mathbf{p}$ & $\left.0.05^{*}\right)$ & 0.70 & 0.27 & 0.41 \\
\hline $\mathbf{p}^{*}$ & 0.18 & 0.52 & 0.23 & 0.53 \\
\hline
\end{tabular}

$\mathrm{X}$-axe Right: The coordinate on $\mathrm{x}$-axes concerning right oriented movement.

X-axe Left: The corresponding coordinate to the left. Y-axe Right: The corresponding Y-axes to the right. Y-axes Left: The corresponding $Y$-axes to the left. The $25^{\text {th }}$ and $75^{\text {th }}$ percentiles are shown in parenthesis. The $\mathrm{p}$-value for pre-and post-treatment differences in each patient group are shown in brackets; *; ** *** express degrees of significance, i.e., ${ }^{*} \mathrm{p}<0.05 ;{ }^{* *} \mathrm{p}<0.01 ;{ }^{* * *} \mathrm{p}<0.001$.

$p$ indicates the $p$-value of the variance analysis of the two patient groups.

$\mathbf{p}^{*}$ indicates the $\mathrm{p}$-value of the variance analysis of the patient- and control groups

Table 2. (A and B) The results of JPE-test for the patients with INDD and WAD at the start (table 2A) and end (table 2B) of the treatment and healthy controls. 
The INDD group showed a small significant difference (concerning the $\mathrm{x}$-axis, after rotating to the right) in the JPE-test compared to the WAD group. Otherwise the base-line results were identical. Both groups differed significantly from the healthy control group. It was observed that there were no differences in cervical range of motion (CROM) between the INDD group and the WAD group. Before start of treatment all subjects had either an abnormal Romberg or One-leg stand test, or both. The various levels of pain were equal in both groups. The questionnaire results and the degree of sick leave were also alike in the two patients groups.

\subsection{The post-treatment state}

The patients in this study received an average of fourteen treatments. Patients with INDD received fourteen treatments with a range between 5 and 26. The WAD group received thirteen treatments with a range between 8 and 28 . The compliance was nearly one hundred percent.

\subsection{Objective tests}

Post-treatment, a significant improvement in the JPE-test was observed in both groups, and variance analysis showed no differences between any of the groups, including the healthy controls. A better co-ordination, e.g. less ataxia of the movement was observed.

\begin{tabular}{|c|c|c|c|c|c|c|c|c|c|}
\hline $\begin{array}{c}\text { Pre- } \\
\text { treatment }\end{array}$ & $\begin{array}{c}\text { Neck } \\
\text { resting }\end{array}$ & Flexion & Extension & $\begin{array}{c}\text { Lateral } \\
\text { flexion } \\
\text { right }\end{array}$ & $\begin{array}{c}\text { Lateral } \\
\text { flexion } \\
\text { left }\end{array}$ & $\begin{array}{c}\text { Rotation } \\
\text { right }\end{array}$ & $\begin{array}{c}\text { Rotation } \\
\text { left }\end{array}$ & $\begin{array}{c}\text { Lateral } \\
\text { symmetry }\end{array}$ & $\begin{array}{c}\text { Rotator } \\
\text { symmetry }\end{array}$ \\
\hline INDD & $\begin{array}{c}5(5-10) \\
\text { extension }\end{array}$ & $40(25-50)$ & $0(0-55)$ & $\begin{array}{c}25 \\
(20-35)\end{array}$ & $\begin{array}{c}30 \\
(20-40)\end{array}$ & $50(35-65)$ & $55(45-65)$ & $5(5-10)$ & $10(0-15)$ \\
\hline WAD & $\begin{array}{c}10(5-10) \\
\text { extension }\end{array}$ & $20(20-45)$ & $15(0-30)$ & $\begin{array}{c}25 \\
(20-30)\end{array}$ & $\begin{array}{c}30 \\
(20-40)\end{array}$ & $45(35-55)$ & $55(30-60)$ & $10(5-15)$ & $10(5-15)$ \\
\hline p-value & 0.13 & 0.051 & 0.88 & 0.51 & 0.71 & 0.44 & 0.34 & 0.10 & 0.76 \\
\hline
\end{tabular}

\begin{tabular}{|c|c|c|c|c|c|c|c|c|c|}
\hline $\begin{array}{c}\text { Post- } \\
\text { treatment }\end{array}$ & $\begin{array}{c}\text { Neck } \\
\text { resting }\end{array}$ & Flexion & Extension & $\begin{array}{c}\text { Lateral } \\
\text { flexion } \\
\text { right }\end{array}$ & $\begin{array}{c}\text { Lateral } \\
\text { flexion } \\
\text { left }\end{array}$ & $\begin{array}{c}\text { Rotation } \\
\text { right }\end{array}$ & $\begin{array}{c}\text { Rotation } \\
\text { left }\end{array}$ & $\begin{array}{c}\text { Lateral } \\
\text { symmetry }\end{array}$ & $\begin{array}{c}\text { Rotator } \\
\text { symmetry }\end{array}$ \\
\hline INDD & $\begin{array}{c}0(0-0) \\
\text { extension } \\
{[0.0001]^{* * *}}\end{array}$ & $\begin{array}{c}35(25-45) \\
{[0.56]}\end{array}$ & $\begin{array}{c}40(0-55) \\
{[0.038]^{*}}\end{array}$ & $\begin{array}{c}35(30-40) \\
{[0.007]^{* *}}\end{array}$ & $\begin{array}{c}35(30-40) \\
{[0.117]}\end{array}$ & $\begin{array}{c}60(50-65) \\
{[0.024]^{*}}\end{array}$ & $\begin{array}{c}60(50-65) \\
{[0.091]}\end{array}$ & $\begin{array}{c}0(0-5) \\
{[0.0006]^{* * *}}\end{array}$ & $\begin{array}{c}0(0-5) \\
{[0.0004]^{* * *}}\end{array}$ \\
\hline WAD & $\begin{array}{c}0(0-5) \\
\text { extension } \\
{[0.0004]^{* * *}}\end{array}$ & $\begin{array}{c}30(25-45) \\
{[0.039]^{*}}\end{array}$ & $\begin{array}{c}50(0-55) \\
{[0.005]^{* *}}\end{array}$ & $\begin{array}{c}35(30-40) \\
{[0.003]^{* *}}\end{array}$ & $\begin{array}{c}35(30-40) \\
{[0.012]^{*}}\end{array}$ & $\begin{array}{c}60(50-60) \\
{[0.003]^{* *}}\end{array}$ & $\begin{array}{c}60(50-60) \\
{[0.03]^{*}}\end{array}$ & $5(0-5)$ & $0(0.0007]^{* * *}$ \\
{$[0.0009]^{* * *}$} \\
\hline p-value & 0.59 & 0.70 & 0.60 & 0.79 & 0.92 & 0.38 & 0.42 & 0.20 & 0.87 \\
\hline
\end{tabular}

All positions and movements were tested without any increase in pain. Neck resting posture in sitting. Flexion, extension, lateral flexion to the right respective to the left as well as rotation to the right and left. Lateral symmetry difference between right- and left-sided lateral flexion. Rotator symmetry differences between right- and left-sided rotations.

The $25^{\text {th }}$ and $75^{\text {th }}$ percentiles are shown in parenthesis. The $\mathrm{p}$-value for pre-and post-treatment differences are shown in brackets; ${ }^{*} ; * ;$; $* * *$ express degrees of significance, i.e. ${ }^{*} p<0.05 ;{ }^{* *} p<0.01$; ${ }^{* * *} \mathbf{p}<0.001$. $\mathbf{p}$-value indicates the variance analysis of the two patient groups.

Table 3. (A and B) Neck range of motion (in degrees) for the patients with INDD and WAD at the start and at the end of the treatment.

Post-treatment a significant improvement in CROM was observed in both groups. 
Concerning balance, both groups improved. Four patients with INDD and three patients with WAD had milder divergences at Romberg and/or One-leg stand test.

\subsection{Pain, dizziness, tinnitus and activities of daily living}

The level of pain was equal in both groups pre-treatment and decreased equally and significantly during therapy. Pre-treatment, all patients suffered from dizziness and disturbed balance. All improved, among the subjects with INDD 23 out of 27 were free from vertigo and dizziness, four had milder symptoms. After treatment 16 out of the 19 patients with WAD had no dizziness, the rest had milder symptoms. Eleven out of eighteen with INDD and six out of eight patients with WAD had reduced tinnitus. In total three out of all patients had the experience of being cured. All aspects of disability improved significantly, which is confirmed through an increased stable working capability.

\begin{tabular}{|c|c|c|c|c|}
\hline & INDD-max pain & $\begin{array}{c}\text { INDD-average } \\
\text { pain }\end{array}$ & WAD-max pain & WAD-average pain \\
\hline Pre-treatment & $7.5(5-8.5)$ & $4.5(3.5-6)$ & $8.5(7.5-10)$ & $5(3.5-5.5)$ \\
\hline Post-treatment & $0(0-4)[0.0001]^{* * *}$ & $1(0.5-3)[0.0000]^{* * *}$ & $0(0-0)[0.0003]^{* * *}$ & $1.5(0.5-2)[0.0001]^{* * *}$ \\
\hline $\begin{array}{c}\text { P -value pre- } \\
\text { treatment }\end{array}$ & $0.019^{*}$ & 0.94 & $0.019^{*}$ & 0.94 \\
\hline $\begin{array}{c}\text { P-value post- } \\
\text { treatment }\end{array}$ & 0,55 & 0,67 & 0,55 & 0,67 \\
\hline
\end{tabular}

From 0 to 10 , where 0 means no pain and 10 the worst pain imaginable. The $25^{\text {th }}$ and $75^{\text {th }}$ percentiles are shown in parenthesis. The p-value for pre-and post-treatment differences are shown in brackets. p-value indicates the variance analysis of the two patient groups for pre- and post-treatment results.

Table 4. Visual analogue scale (VAS-score) (pain) for the patients with INDD and WAD.

\begin{tabular}{|c|c|c|c|c|c|c|c|}
\hline $\begin{array}{c}\text { Pre- } \\
\text { treatment }\end{array}$ & $\begin{array}{c}\text { Concentra- } \\
\text { tion }\end{array}$ & Tiredness & Socializing & $\begin{array}{c}\text { Physical } \\
\text { activity }\end{array}$ & Sleep & $\begin{array}{c}\text { Working/ } \\
\text { householding }\end{array}$ & Car-driving \\
\hline INDD & $6(4.5-7)$ & $6(5-8)$ & $6(5-7.5)$ & $7(6-9)$ & $6(2.5-7.5)$ & $8(6-8.5)$ & $3.5(0-6)$ \\
\hline WAD & $7.5(5-9)$ & $7.5(6.5-8.5)$ & $7.5(6-9)$ & $8.5(7.5-9.5)$ & $7.5(6-8.5)$ & $8.5(7-9.5)$ & $6(0-8)$ \\
\hline p-value & $0.024^{*}$ & 0.074 & 0.196 & 0.199 & $0.049 *$ & 0.462 & 0.233 \\
\hline
\end{tabular}

\begin{tabular}{|c|c|c|c|c|c|c|c|}
\hline $\begin{array}{c}\text { Post- } \\
\text { treatment }\end{array}$ & $\begin{array}{c}\text { Concentra- } \\
\text { tion }\end{array}$ & Tiredness & Socializing & $\begin{array}{c}\text { Physical } \\
\text { activity }\end{array}$ & Sleep & $\begin{array}{c}\text { Working/ } \\
\text { householding }\end{array}$ & Car-driving \\
\hline INDD & $\begin{array}{c}3(2-4) \\
{[0.0000]^{* * *}}\end{array}$ & $\begin{array}{c}2.5(2-4) \\
{[0.0000]^{* * *}}\end{array}$ & $\begin{array}{c}2.5(1-4) \\
{[0.0000]^{* * *}}\end{array}$ & $\begin{array}{c}2.5(1-4) \\
{[0.0000]^{* * *}}\end{array}$ & $\begin{array}{c}2(0.5-4) \\
{[0.0000]^{* * *}}\end{array}$ & $\begin{array}{c}3(2.5-4) \\
{[0.0000]^{* * *}}\end{array}$ & $\begin{array}{c}1(0-2.5) \\
{[0.0003]^{* * *}}\end{array}$ \\
\hline WAD & $\begin{array}{c}3(2-5) \\
{[0.0003]^{* * *}}\end{array}$ & $\begin{array}{c}3(1.5-3) \\
{[0.0001]^{* * *}}\end{array}$ & $\begin{array}{c}3(1.5-4) \\
{[0.0003]^{* * *}}\end{array}$ & $\begin{array}{c}3(2-4) \\
{[0.0003]^{* * *}}\end{array}$ & $\begin{array}{c}2(2-3) \\
{[0.0003]^{* * *}}\end{array}$ & $\begin{array}{c}2.5(1.5-4.5) \\
{[0.0001]^{* * *}}\end{array}$ & $\begin{array}{c}2(0-2.5) \\
{[0.0015]^{* *}}\end{array}$ \\
\hline p-value & 0.459 & 0.655 & 0.600 & 0.524 & 0.894 & 0.233 & 0.610 \\
\hline
\end{tabular}

From 0 to 10 , where 0 means no influence and 10 the worst impact imaginable. The $25^{\text {th }}$ and $75^{\text {th }}$ percentiles are shown in parenthesis. The $p$-value for pre-and post-treatment differences are shown in brackets; *; ${ }^{* *}$; ${ }^{* *}$ express degrees of significance, i.e. ${ }^{*} p<0.05 ;{ }^{* *} p<0.01 ;{ }^{* * *} p<0.001$.

p-value indicates the variance analysis of the two patient groups.

Table 5. (A and B) Visual analogue scale (VAS-score) (impact upon daily living activities) for the patients with INND and WAD. 
Nearly all the subjects experienced improved work capacity. Before treatment only two subjects from a total of 27 (i.e. $7 \%$ ) with INDD were working more than $50 \%$. Three had disability pension. Three months post-treatment, 21 out of the 27 persons worked half-time or more. Six of them worked $100 \%$. This means that $78 \%$ of the INDD patient group worked half-time or more, three months post-treatment. It was observed that fewer subjects in the INDD group than among the patients with WAD reached a $100 \%$ working capacity. Before treatment, two out of nineteen (i.e. 11\%) subjects with WAD worked half-time or more. Six individuals had disability pension. Three months post-treatment, 14 out of the 19 persons worked half-time or more. Seven of them worked $100 \%$. This means that $74 \%$ of the WAD patient group worked half-time or more, three months post-treatment. Three subjects with disability pension went back to work half-time.

\section{References}

[1] Möller AA: "Hearing: Anatomy, Physiology, and Disorders of the auditory system ", Elsevier, Academic Press, San Diego, 2006.

[2] Baloh R, Halmagyi G: Disorders of the vestibular system. New York: Oxford University press; 1996.

[3] Brandt T: Vertigo, its multisensory syndromes. London: Springer; 1999.

[4] Lorento de-No: Vestibulo-ocular reflex arc. Arch Neurol Psychiatry 1933, 30:245-291.

[5] Highstein SM: Role of the flocculus of the cerebellum in motor learning of the vestibuleocular reflex. Otolaryngol Head Neck Surg 1998, 119(3):212-220.

[6] Green AM, Angelaki DE: Internal models and neural computation in the vestibular system. Exp Brain Res 2010, 200 (3-4):197-222.

[7] Donaldson IM: The functions of the proprioceptors of the eye muscles. Philos Trans $R$ Soc Lond B Biol Sci 2000; 355 (1404):1685-1754

[8] Weir CR, Knox PC, Dutton GN. Does extraocular muscle proprioception influence oculomotor control? Br J Ophtalmol 2000; 84:1071-74

[9] Balslev D, Albert NB, Miall C: Eye muscle proprioception is represented bilaterally in the sensorimotor cortex. Hum Brain Mapp 2011; 32(4):624-631.

[10] Bacsi AM, Colebatch JG: Evidence for reflex and perceptual vestibular contributions to postural control. Exp Brain Res 2005, 160(1):22-28.

[11] Tellegen AJ, Arends JJ, Dubbeldam JL: The vestibular nuclei and vestibuloreticular connections in the mallard (Anas platyrhynchos L.) An anterograde and retrograde tracing study. Brain Behav Evol 2001, 58(4):205-217.

[12] Goldberg JM, Cullen KE: Vestibular control of the head: possible functions of the vestibulocollic reflex. Exp Brain Res 2011, 210 (3-4):331-345.

[13] Hillier SL, McDonnell M: Vestibular rehabilitation for unilateral peripheral vestibular dysfunction. Cochrane Database Syst Rev 2011, Feb 16;2:CD005397.

[14] Hebb DO. The organization of behaviour. New York: Wiley, 1949

[15] Barány R: Diagnose von Krankheitserscheinungen im Bereiche des Otolithenapparates. Acta Otolaryngol (Stockh) 1921, 2:334-337.

[16] Dix R, Hallpike CS: The pathology, symptomatology and diagnosis of certain common disorders of the vestibular system. Ann Otol Rhinol Laryngol 1952, 8:151-158.

[17] Norré ME: Reliability of examination data in the diagnosis of benign paroxysmal positional vertigo. Am J Otol 1995,16(6):806-810. 
[18] Tjell C \& Iglebekk W. Symptoms and findings in a prospective cohort study of the misinterpreted patient with long lasting benign paroxysmal positional vertigo. Journal of Rehabilitation Medicine 2011; Suppl 50: 24.

[19] Spitzer WO, Skovron ML, Salmi LR, Cassidy D, Duranceau J, Suissa S, Zeiss E: Scientific monograph of the Quebec task force on whiplash-associated disorders: redefining "whiplash" and its management. Spine 1995, 20:1-73.

[20] Humphreys BK, Bolton J, Peterson C, Wood A: A Cross-sectional study of the association between pain and disability in neck pain patients with dizziness of suspected cervical origin. J Whiplash Relat Disord 2002, 1(2):63-75.

[21] Hodges PW, Gurfinkel VS, Brumagne S, Smith TC, Cordo PC: Coexistence of stability and mobility in postural control: evidence from postural compensation for respiration. Exp Brain Res 2002; 144:293-302.

[22] Gandevia SC, McCloskey DI, Bruke D. Kinaesthetic signals and muscle contraction. Trends Neurosci 1992; 15: 62-65

[23] Wolpert DM, Ghahramani Z, Jordan MI. An internal model for sensorimotor integration. Science 1995; 269: 1880-1882.

[24] Ghez C, Sainburg R. Proprioceptive control of interjoint coordination. Can J Physiol Pharmacol 1995; 73: 273-284.

[25] Peterson BW, Goldberg J, Biolotto G, Fuller JH. Cervicocollic reflex: its dynamic properties and interaction with vestibular reflexes. J Neurophys 1985; 54: 90 - 109.

[26] Chan YS, Kasper J, Wilson VJ. Dynamics and directional sensitivity of neck musclespindle responses to head rotation. J Neurophysiol 1987; 57:1716-1729.

[27] Peterson BW. Current approaches and future directions to understanding control of head movement. Brain mechanisms for the integration of posture and movement. Prog Brain Res 2004; 143:369-381.

[28] Kulkarni V, Chandy MJ, Babu KS: Quantitative study of muscle spindles in suboccipital muscles of human foetuses. Neurol India 2001, 49:355-359.

[29] Boyd-Clarc LC, Briggs CA, Galea MP: Muscle spindle distribution, morphology, and density in longus colli and multifidus muscles of the cervical spine. Spine 2002, 27 (7): 694-701.

[30] Liu J, Thornell L, Pedrosa-Domellof F: Muscle spindles in the deep muscles of the human neck: a morphological and immunocytochemical study. J Histochem Cytochem 2003, 51:175-186.

[31] Field S, Treleaven J, Jull G. Standing balance. A comparison between idiopathic and whiplash induced neck pain. Man Ther. 2008; 13:183-191

[32] Heikkila H, Astrom PG. Cervicocephalic kinaesthetic sensibility in patients with whiplash injury. J Rehab Med 1996; 28:133-138

[33] Revel M, Minguet M, Gregoy P, Vaillant J, Manuel JL. Changes in cervicocephalic kinaesthesia after a proprioceptive rehabilitation program in patients with neck pain: a randomized controlled study. Arch Phys Med Rehabil 1994; 75: 895-899.

[34] O’Sullivan P, Twomey L, Allison G. Dysfunction of the neuro-muscular system in the presence of low back pain - implications for physical therapy management. Journal of Manual and Manipulative Therapy 1997, 5(1): 20-26

[35] Sjolander P, Michaelson P, Djupsjobacka M. Spinal and supraspinal effects of activity in ligament afferents. Journal of Electromyography and Kinesiology 2002; 12: 167176 
[36] Johansson H, Sjölander P. The neurophysiology of joints. In: Wright V, Radin EL editors. Mechanics of joints: physiology, pathophysiology, and treatment. New York: Marcel Dekker Inc, 1993; pp 243-90.

[37] Djubsjobacka M, Johansson H, Bergenheim M. Inflences on the gamma muscle-spindle system from muscle afferents stimulated by increased intramuscular concentrations of arachidonic acid. Brain Research 1994; 663: 293-302

[38] Thunberg J, Hellstrom F, Sjolander P, Bergenheim M, Wenngren B, Johansson H. Influences on the fusimotor-muscle spindle system from chemosensitive nerve endings in cervical facet joints in the cat: possible implicationsfor whiplash induced disorders. Pain 2001; 91: 15-22.

[39] Hellstrom F, Thunberg J, Bergenheim M, Sjolander P, Djupsjobacka M, Johansson H. Increased intra-articular concentration of bradykinin in the temporomandibular joint changes the sensitivity of muscle spindles in dorsal neck muscles in the cat. Neuroscience research 2002; 42: 91-99

[40] Pedersen J, Ljubisavljevic M, Bergenheim M, Johansson H. Alterations in information transmission in ensembles of primary muscle spindle afferents after muscle fatigue in heteronymous muscle. Neuroscience 1998; 84: 953-59.

[41] Loudon JK, Ruhl M, Field E. Ability to reproduce head position after whiplash injury. Spine 1997; 22: 865-867

[42] Kristjansson E, Dall' Alba P, Jull G. A study of five cervicocephalic relocation tests in three different subject groups. Clinical Rehabilitation 2003; 17: 768-74.

[43] Treleaven J, Jull G, Sterling M. Dizziness and unsteadiness following whiplash injury: characteristic features and relationship with cervical joint position error. J Rehab Med 2003; 35: 36-43.

[44] Kubin K, Manzoni D, Pompeiano O. 1981 Responses of lateral reticular neurons to convergent neck and macular vestibular input. Journal of Neurophysiology 1981; 46: 48-64.

[45] Grüsser O-J, Pause M, Schreiter U. Vestibular neurones in the parieto-insular cortex of monkeys (Macaca fascicularis): visual and neck receptor responses. Jounal of Physiology (London) 1990; 430:559-83.

[46] Popova LB, Ragnarson B, Orlovsky GN. Responses of neurons in the central cervical nucleus of the rat to proprioceptive and vestibular inputs. Arch Ital Biol 1995; 133: 31-45.

[47] Pyykkö I, Schalén L, Wennmo C. Single unit activity in flocculus of alert cat during vestibular, visual and proprioceptive stimulation. Agressologie 1983; 24: 215-216.

[48] Tjell C. Cervicogenic vertigo: with special emphasis on whiplash-associated disorder. In: Vernon $\mathrm{H}$ editor. The cranio-cervical syndrome, mechanisms, assessment and treatment. Oxford: Butterworth Heinemann, 2001; ch 13, pp 231-43.

[49] Jacobson GP, Newman CW: The development of the Dizziness Handicap Inventory. Arch Otolaryngol Head Neck Surg 1990, 116 (4):424-427.

[50] Shumway-Cook A, Brauer S, Woollacott M. Predicting the probability for communitydwelling older adults using the Timed Up \& Go Test. Phys Ther 2000; 80(9):896-903

[51] Brandt T, Daroff RB: Physical therapy for benign paroxysmal positional vertigo. Arch Otolaryngol 1980, 106:484-85.

[52] Tjell C, Rosenhall U. Smooth pursuit neck torsion test: A specific test for cervical dizziness. Am J Otol 1998; 19: 76-81. 
[53] Treleaven J,Jull G, LowChoy N. Smooth pursuit neck torsion test in whiplash associated disorders - Relationship to self reports of neck pain and disability, dizziness and anxiety. J Rehabil Med 2005; 37(4): 219-23.

[54] Tjell C, Iglebekk W. Have we been fooled by BPPV when diagnosing WAD? Only a few seem to have a real neck injury. J Rehabil Med Suppl 2011; 50:24.

[55] Epley JM: The canalith repositioning procedure: for treatment of benign paroxysmal positional vertigo. Otolaryngol Head Neck Surg 1992, 107:399-404.

[56] Epley JM: Positional vertigo related to semicircular canalithiasis. Otolaryngol Head Neck Surg 1995, 112:154-161.

[57] Pinfold M, Niere KR, O’Leary EF, Hoving JL, Green S, Buchbinder R. Validity and internal consistency of a Whiplash-Specific disability measure. Spine 2004; 29(3): 263-268. 


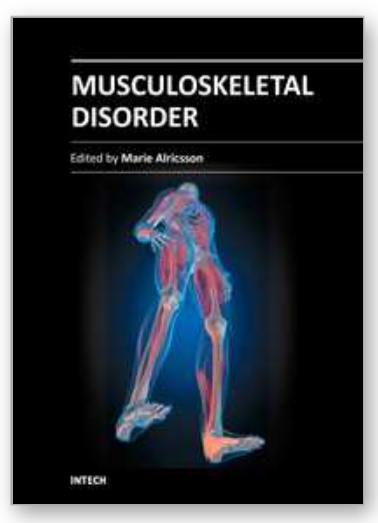

\author{
Musculoskeletal Disorder \\ Edited by Prof. Marie Alricsson
}

ISBN 978-953-51-0485-8

Hard cover, 82 pages

Publisher InTech

Published online 04, April, 2012

Published in print edition April, 2012

Work-related musculoskeletal disorders are a significant problem throughout the world. The work environment has undergone rapid changes in recent years. With increasing number of workers being tied to man, machine systems, susceptibility to constrained postures, visual strain and mental and physical stresses have increased. This book is a collaboration among many clinicians and researchers and a small step in addressing these issues by discussing various aspects of musculoskeletal disorders from different professions, researchers and countries.

\title{
How to reference
}

In order to correctly reference this scholarly work, feel free to copy and paste the following:

Carsten Tjell and Wenche Iglebekk (2012). Postural Mismatch in Musculoskeletal Disorders, Musculoskeletal Disorder, Prof. Marie Alricsson (Ed.), ISBN: 978-953-51-0485-8, InTech, Available from:

http://www.intechopen.com/books/musculoskeletal-disorder/postural-mismatch-of-musculoskeletal-disorders

\section{INTECH}

open science | open minds

\section{InTech Europe}

University Campus STeP Ri

Slavka Krautzeka 83/A

51000 Rijeka, Croatia

Phone: +385 (51) 770447

Fax: +385 (51) 686166

www.intechopen.com

\section{InTech China}

Unit 405, Office Block, Hotel Equatorial Shanghai

No.65, Yan An Road (West), Shanghai, 200040, China

中国上海市延安西路65号上海国际贵都大饭店办公楼 405 单元

Phone: +86-21-62489820

Fax: $+86-21-62489821$ 
(C) 2012 The Author(s). Licensee IntechOpen. This is an open access article distributed under the terms of the Creative Commons Attribution 3.0 License, which permits unrestricted use, distribution, and reproduction in any medium, provided the original work is properly cited. 